\title{
EDITORIAL
}

\section{Corazón y mente, ¿quién manda a quién? ${ }^{\text {‘s }}$}

\section{Heart and mind who sends whom?}

\section{Guillermo Sánchez-Medina}

\author{
Academia Nacional de Medicina, Bogotá, Colombia
}

Recibido el 13 de febrero de 2018; aceptado el 14 de febrero de 2018

Disponible en Internet el 10 de marzo de 2018

El Profesor Darío Echeverri me solicitó un escrito sobre esta temática de corazón o mente ¿quién manda a quién?, que si bien ha sido un tema discutido desde lo griegos, hoy día las neurociencias aclaran la respuesta; sin embargo, voy a permitirme hacer una "nanosíntesis" histórica respecto a estos conceptos.

Aristóteles creía que el corazón era la sede de la sensación y de las emociones ${ }^{1}$, concepto que prevaleció en la antigüedad desde la edad media hasta el siglo xvı; en el mismo Nuevo Testamento se habla de la relación del hombre consigo mismo, ya sea en el deseo ${ }^{2}$. Hasta ese entonces se fusionaban las sensopercepciones, el pensamiento y la voluntad.

El uso moderno de la palabra corazón se originó sin duda con Pascal $^{3}$, quien se refirió a razones del corazón ${ }^{4}$. Este pensador le atribuyó dos especies de conocimiento específico: el de las relaciones humanas y de todo de lo que ella nace, de tal manera que el corazón es guía privilegiada en el hombre en el dominio de la moral, la religión, la filosofía y la elocuencia, y el conocimiento de los principios de la ciencia, especialmente de la matemática ${ }^{3}$. Si reflexionamos profundamente, el corazón es un órgano que es parte de todo un sistema en el cual participa la temporoespacialidad y los conceptos de finito e infinito. De otra

Correo electrónico: guillermosanchezmedina@yahoo.es parte, el filósofo Hegel entendía por el corazón "al conjunto de la sensación" o de la "experiencia" y puntualizó que no bastaba que los principios éticos y estéticos estuvieran en la cabeza, puesto que debían estar en el corazón, más cuando era él, el que producía las sensaciones. Aún más, se construyó una ley del corazón con sus necesidades, exigencias, evolución, principio y fin; como siempre, las leyes creadas por el hombre tienen laxitudes o rigideces que a veces molestan o atormentan al ser humano.

En la filosofía moderna se habla de las necesidades del alma, del sentimiento, de la esperanza, y ubican al corazón como el símbolo de aquellas creencias incluyendo en el proceso valores humanos y el destino. De tal manera que el término corazón se usa a la vez con el de la consciencia, de las realidades y con absoluta certeza; no obstante, este pensamiento es parcializante, puesto que el corazón solamente es un órgano fundamental que recibe sangre e impulsa la misma para ser "oxigenada" en los pulmones y volver a éste para lanzarle a los nueve diferentes sistemas biopsicológicos que mantienen al ser humano vivo. El flujo sanguíneo contiene las diferentes moléculas, átomos con los programas químico cuánticos, los cuales son responsables de las funciones vitales. Estos sistemas operan en una interrelación cerebro-mente, materia-energía con los conceptos de red de los mismos sistemas, los cuales se estudian, no solo por la biología molecular (con las organizaciones proteicas, peptídicas, las cuales participan en el control de la 
dinámica cerebral con sus neurotransmisores y neurorreceptores químico-eléctricos, a través de moléculas químicas y obviamente llegan al cerebro, a la glía, a sus redes, a la sinapsis), por las neurociencias, las matemáticas, el álgebra, el cálculo y la estadística, sino también por la geometría y la mecánica ondulatoria cuántica con sus "funciones de onda" y todo el sistema neuropsicológico (sistémico, cognitivo, dinámico, conductual, grupal, etc.). Entendamos que todos estos sistemas funcionan gracias a las fuerzas energéticas conocidas de la gravedad, la electromagnética y las nucleares débiles de la cual se deriva la física cuántica con sus partículas elementales (quarks, leptones, bosones, fotones y gluones).

De lo expuesto se deduce cómo la integración de sistemas participa directamente entre la información cerebral o neuronal o los diferentes sistemas ya mencionados, con la capacidad de aprendizaje a la memoria; así, entonces, cualquier patología se expresará primordialmente en algún sistema, pero conlleva indefectiblemente una alteración en el resto del circuito en el cual se incluye el sistema cardiovascular y el pulmonar.

Entendamos que el "yo del sujeto", está dividido en dos: el psíquico y el corporal, los cuales funcionan en una interrelación; el primero construye representaciones de lo perceptivo y de lo imaginativo del imaginario (individual y colectivo o lo que se denomina fantasía inconsciente), y el segundo (el yo corporal) también es representando en cada uno de los órganos y sistemas, según sus funciones (por ejemplo, ojos, nariz, oídos, lengua, piel, etc...) La representación tiene su significado y sentido de las mismas; por ejemplo, en el sistema cardiorrespiratorio éste es estimulado desde la médula superior y protuberancia, a la vez que con estímulos del hipotálamo o "cerebro emocional"; los estímulos son conducidos por los sistemas nervioso central y neurovegetativo (simpático y parasimpático) con los neurotransmisores y receptores para configurar acciones con frecuencias ondulatorias que llevan los mensajes al órgano para estimularlo, y, a la vez, al cerebro, a las circunvoluciones occipitales frontales motoras y parietales sensitivas; así se configuran las representaciones que son ligadas a las emociones, los afectos y sentimientos, interviniendo e interrelacionándose con las funciones cardiovasculares.

Conocemos bien que el corazón con su contracción sistónica, bombea la sangre por todo el cuerpo. Gracias a esta contracción el cerebro puede funcionar, pensar y actuar con decisiones; estas y muchas más funciones las hace el cerebro siempre y cuando le llegue sangre, la cual no se hace o se origina en el corazón, pero éste sí maneja la fuerza de la gravedad para irrigar todo el cuerpo con todo su contenido que da vida al ser.

Entre los sistemas integrados se incluye el endocrino y, obviamente, el hormonal, el cual también participa en las funciones cardiacas.

Téngase en cuenta que cada órgano tiene su simbolización y/o es utilizado para simbolizar necesidades, deseos, impulsos, tendencias afectivas fantásticas y emocionales, en las cuales existe la actividad, el movimiento, la vida y sus contrarios: pasividad, quietud o parálisis o inmovilización, y la muerte, no sin pasar por alteraciones en sus funciones.

Ahora ocupémonos más puntualmente en qué es la mente o la psiquis y el pensar. ¿Qué entendemos por mente, cómo es ella y dónde opera? La respuesta debe abordarse con el concepto de que "mente es una facultad" por medio de la cual se "efectúan los pensamientos" ("se piensa con pensamientos" pertenecientes a la mente la cual es una función del cerebro); el término se asocia con la inteligencia, con el ser consciente y la consciencia así como el inconsciente. Muchos de los filósofos, teólogos y aun científicos analizan o ubican a la mente como sinónimo de la psiquis, e históricamente tiene analogía con el alma; es por esto por lo que a lo psíquico se le da referencia a lo perteneciente al alma, al psiquismo o al conjunto de características e inclusiones de la actividad mental. Aquí lo importante es diferenciar los conceptos de connotación religiosa (alma) y científica (mente o psiquis).

Partamos de la etimología latina; la palabra "mens" significa mente, alma, espíritu con todas sus connotaciones. El diccionario de la Real Academia Española ${ }^{5}$, define mente $^{*}$ (mens) como la potencia intelectual del alma y en su segunda acepción se refiere "al designio, el pensamiento, al propósito y la voluntad"'. En el diccionario de uso del español de María Moliner ${ }^{6}$, la mente se relaciona con la facultad con que se piensa, "la inteligencia", el "estar en" y el "pensamiento". De todo esto podemos sintetizar que la mente es un concepto global (unitario) de las funciones que animan el cerebro y que se relaciona con la inteligencia, la razón, la memoria, la imaginación, la intencionalidad, la decisión, la voluntad, el pensamiento, el conocimiento y la consciencia. He ahí una descripción de parte de las funciones mentales que se originan en el cerebro como son las sensoperceptivas, la comprensión y toda una serie de patrones (con sus funciones) que aparecen descritos mediante los cuatro ejes del pensar.

Por milenios se entendió que los fenómenos mentales no tenían nada que ver con la física, puesto que carecían de forma, de materia y hasta cierto punto se pensaba que sólo nos encontrábamos con lo abstracto. Sin embargo, existe un límite entre lo físico (materia-energía-función de ondapartículas cuánticas) y el producto o resultado que es el fundamento esencial, o el "ente" que expresa y comunica el sí mismo con el afuera a través de la palabra. La misma palabra mente ( $\mathrm{m}$ - ente) nos lleva a pensar en la segunda parte, "ente" que viene de "ens", "entis", que significa "ser", "lo que existe"'. De ahí, podemos asociar y concluir que el "estar" y el "ser" se unen en la palabra "mente" y al mismo tiempo es el fundamento y lo que caracteriza al ser que es la mente con sus diferentes funciones y entre ellas la inteligencia que se utiliza para comprender y la consciencia para ser consciente de ello ${ }^{7}$.

Para finalizar la pregunta ¿quién manda a quién: corazón o mente en su integración? La respuesta es que si falla

\footnotetext{
* La palabra "mente"' puede utilizarse como un sufijo para formar adverbios añadiéndolo al final del adjetivo, por ejemplo: discretamente, públicamente, enérgicamente, radicalmente, etc. ¿Por qué ocurre esto? La respuesta posible se basa en que agregando el sufijo "mente" se le dan fuerza y dirección al adjetivo ubicándolo en la "mente". Si hacemos la descomposición de la palabra en: "mens" (o sólo pronunciando la letra m), y "ente"; encontramos que en realidad se requiere de un "sujeto"' que sujete el "objeto" sensopercibido o "sentido", o "conocido", o "que se da cuenta que lo siente"; es decir, se requiere de un sujeto o ente que se dé cuenta de lo que siente en su cuerpo, por los órganos de los sentidos. Así llegamos por asociación y conexión a la palabra "mente".
} 
el corazón puede haber repercusiones mentales y si es lo opuesto el corazón funciona independiente del trastorno psíquico; por ejemplo, son diferentes los síntomas en el Alzheimer, el Parkinson, la "bipolaridad", la psicosis paranoide, etc. Lo que sí se debe reflexionar es cómo un estímulo electroquímico se produce para cambiar una función, y lo hace por alteración, carencia, necesidad, falla en la función o por desgaste, o por la llamada "fatiga-estrés" y aún en la falta de la telomerasa, con lo cual hay fallas sistémicas moleculares y obviamente de sus gradientes que no le permiten, no solo los estímulos adecuados sino la proliferación de las moléculas. Pensemos que ya existen trasplantes de corazón, pero no de cerebro. Ahora reflexionemos que si nos movemos, pensamos y sentimos es porque estamos vivos; sin embargo, si no hay capacidad de pensar, sentir, y movernos es una falla severa; obviamente "la mente tiene razones que el corazón no comprende, porque no tiene capacidad de pensar"'; decía Descartes: "pienso, luego existo"'; yo agregaría pienso, siento, luego vivo. Todo esto se organiza y se comanda en el cerebro, y no en el corazón.

\section{Lectura recomendada}

1. Abbagnano N. Diccionario de filosofía. Bogotá: Fondo de Cultura Económica; 1963.

2. Sagrada Biblia.

3. Pensées, 277.

4. Pascal J. Jung para la vida cotidiana. Ed. Obelisco; 1998.

5. Diccionario de la Lengua Española. Madrid, España: Ed. Tricentenario; 2014

6. Moliner M. Diccionario de uso del español. Segunda edición; 2002.

7. Sánchez Medina G, Márquez Díaz JE. Cerebro y mente: el pensamiento cuántico; 2009. 